\title{
Proteomic Analysis of Celecoxib on Chondrocytes from Patients with Osteoarthritis
}

\author{
Kenji Takenouchi' ${ }^{1}$, Mitusmi Arito' ${ }^{2}$, Toshiyuki Sato ${ }^{2}$, Kenji Takahashi', \\ Manae S. Kurokawa' ${ }^{2}$, Kazuo Yudoh ${ }^{3}$, Shinro Takai', Tomohiro Kato², Hiroshi Nakamura ${ }^{*}$ \\ ${ }^{1}$ Department of Orthopaedic Surgery, Nippon Medical School, Tokyo, Japan \\ ${ }^{2}$ Clinical Proteomics and Molecular Medicine, St. Marianna University Graduate School of Medicine, Kawasaki, \\ Japan \\ ${ }^{3}$ Department of Frontier Medicine, Institute of Medical Science, St. Marianna University Graduate School of \\ Medicine, Kawasaki, Japan \\ Email: ${ }^{*}$ nakamura@nms.ac.jp
}

Received 27 May 2014; revised 20 June 2014; accepted 18 July 2014

Copyright (C) 2014 by authors and Scientific Research Publishing Inc.

This work is licensed under the Creative Commons Attribution International License (CC BY).

http://creativecommons.org/licenses/by/4.0/

(c) (i) Open Access

\begin{abstract}
Objective: To study a comprehensive proteomic analysis of celecoxib in oseteoarthritis (OA) chon-


celecoxib. Proteins were extracted from the cells and subjected to 2-dimensional differential image gel electrophoresis (2D-DIGE). Proteins of interest were identified by mass spectrometry. Results: Eighty-six protein spots showed significantly different intensities with each reagent or reagent combination. AAA+ protein, HSP47/Serpin, cAMP-dependent protein kinase type II-beta regulatory subunit, alpha-actin-4 and tubulin decreased with the addition of celecoxib, while apolipoprotein $A-V$, glutamate carboxipeptide 2 , mitochondrial stress-70 protein, sorting nexin-9 and GRP78 increased with the addition of celecoxib. GRP78 is a stress protein and may be chondroprotective. Celecoxib modulated IL-1 $\beta$ stimulated chondrocytes, and CD200R and moesin were identified as such resulting proteins. Conclusion: Protein profiles of $O A$ chondrocytes changed after administration of celecoxib. Further investigation is needed to elucidate the function of each protein in $\mathrm{OA}$ chondrocytes.
\end{abstract}

\section{Keywords}

Proteomic Analysis, Celecoxib, Chondrocytes, Osteoarthritis

\footnotetext{
*Corresponding author.
} 


\section{Introduction}

Osteoarthritis (OA) is a common joint disorder affecting elderly populations. The prevalence of radiographic knee OA in adults was reported as $37.4 \%$ in the USA and $61.9 \%$ in Japan, and it increased with age [1] [2]. Indirect and nonmedical costs for OA have significant implications, given its high prevalence and an upcoming aging society [3].

One of the characteristic changes in OA is wear and tear of articular cartilage. Chondrocytes are the only cellular component in articular cartilage, and they maintain homeostasis of articular cartilage synthesizing matrix molecules such as collagen and proteoglycan. In OA, cartilage homeostasis is disrupted by the loss of balance between cartilage anabolism and catabolism [4]. Cytokines modulate the degradation of articular cartilage. Interleukin-1 (IL-1) plays a central role in the pathogenesis of OA [5]. IL-1 is present in OA chondrocytes [6], and it stimulates chondrocytes to produce chemical mediators such as prostaglandin $\mathrm{E}_{2}$, nitric oxide and metalloproteinases [7]-[9]. These mediators have catabolic effects on cartilage [10].

There are no evident treatments that cure OA or delay the disease progression as yet. Thus, the current goal of treatment is to modify symptoms of OA. Some guidelines recommend NSAIDs including selective COX-2 inhibitors [11] [12]. However, conventional NSAIDs have serious adverse effects and degrade articular cartilage [13]-[15]. In our in vitro experiments, both diclofenac and celecoxib induced apoptosis in chondrocytes in a dose-dependent manner, however the latter induced it to a lesser degree [16]. Recently, celecoxib is suggested to have potential disease-modifying properties in OA [17]. Thus, celecoxib might be preferable to use for the treatment of OA. The aim of this study is to identify potent candidate proteins that are targets of celecoxib in OA chondrocytes.

To investigate cellular phenotypes under different conditions, a method of comprehensive analysis of proteins has been developed [18] [19]. In the present study, chondrocytes from OA patients were prepared under four different conditions: 1) unstimulated (control), 2) treated with IL-1 $\beta$, 3) treated with IL-1 $\beta$ and celecoxib, and 4) treated with celecoxib. To simulate in vivo conditions of OA, chondrocytes were stimulated with IL- $1 \beta$, and celecoxib was added to simulate the clinical effects of celecoxib [16]. Moreover, stimulation by celecoxib alone was considered to reflect the effects of celecoxib on senescent chondrocytes.

\section{Materials and Methods}

\subsection{Clinical Samples and Preparation of Chondrocytes}

Human articular chondrocytes were obtained from 3 patients with OA (3 females, mean age, 73.3 years) who underwent knee joint arthroplasty. They fulfilled criteria of OA [20]. The patients were treated with neither NSAIDs nor celecoxib at least one month prior to the operation. Written informed consent was obtained from each patient and the study protocol was approved by the ethics committee of Nippon Medical School. The study was performed in compliance with the World Medical Association Declaration of Helsinki (1964).

After careful removal of synovial tissue, cartilage was minced, washed, and treated with collagenase. Isolated chondrocytes were then washed and grown in vitro in monolayer culture in Dulbecco's modified Eagle's medium (DMEM, GIBCO, Carlsbad, CA) supplemented with 10\% fetal calf serum (FCS) and antibiotics. The attached cells (P0) were expanded on type I collagen-coated culture dishes (P1 or P2), which were used in the experiments.

\subsection{In Vitro Stimulation of Chondrocytes}

Chondrocytes $\left(1.0 \times 10^{7}\right.$ cells/ $\phi 100 \mathrm{~mm}$ type I collagen-coated dish) were cultured in the medium containing 5 ng/ml IL-1 $\beta$ (R \& D, Minneapolis, MN, USA), $100 \mu \mathrm{M}$ celecoxib (a gift from Pfizer), or both for 24 hours. Chondrocytes for negative control were cultured without the reagents for 24 hours. Though the clinical relevant concentration of celecoxib is as low as $10 \mu \mathrm{M}$ [21], the higher concentration was used to enhance the cellular effects and to reveal the full spectrum of the pharmacological activities of celecoxib. Then the chondrocytes were harvested and cellular proteins were extracted into a lysis buffer (4\% 3-[(3-cholamidopropyl) dimethylamino]-1-propanesulfonate/7 mol urea/2 molthiourea/30 mmol Tris $\mathrm{pH} 8.0$ ).

\subsection{2-Dimensional Differential Image Gel Electrophoresis (2D-DIGE) [19]}

An equal amount of the 12 protein samples (Il-1 $\beta$-treated, celecoxib-treated, both-treated, and control, $\mathrm{n}=3$ ) 
were mixed and labeled with Cyanine dyes 3 (Сy3, Cy Dye DIGE Saturation dye; GE Healthcare, Buckinghamshire, UK) for internal standard. Similarly, each of the protein samples was labeled with Cyanine dyes 5 (Cy5). Then $2.5 \mu \mathrm{g}$ of the Cy3-labeled mixed sample (standard sample) and $2.5 \mu \mathrm{g}$ of the Cy5-labeled individual samples were mixed and applied onto an isoelectric focusing (IEF) gel (pH 3 - 11; GE Healthcare). After IEF, the proteins were further separated by sodium dodecyl sulfate-polyacrylamide gel electrophoresis (SDS-PAGE). Then the gel images were obtained by an image analyzer (Typhoon). To compare protein spot intensity among the 4 groups, Cy5-fluorescent intensity of protein spots in each gel was normalized by Cy3-fluorescent intensity of identical spots by using the Progenesis program (Nonlinear Dynamics, Newcastle, UK), and the normalized Cy5-intensity was used for the comparison. In addition, 50 micrograms of proteins, labeled with Cy3, were used in 2DE for protein identification.

\subsection{Protein Identification}

For identification of proteins, 2-DE gel fragments with approximately $1 \mathrm{~mm}$ in diameter, which corresponded to protein spots of interest, were recovered. The protein in the gel fragment was digested with trypsin and the resulting peptides were recovered as described previously [19]. Masses of the digested peptides and their collision induced dissociation (CID) fragments were determined using a MALDI-TOF/TOF MS (Ultraflex, BurkerDaltonics, Germany). The MS/MS spectra obtained were used for searching of the National Center for Biotechnology Information protein database using the Mascot software program (Matrix Science, London, UK).

\subsection{Statistical Analysis}

Statistical significance was calculated by Student's $t$-test.

\section{Results}

To investigate whether celecoxib affects protein profiles of chondrocytes, and also whether celecoxib modulates the effects of IL- $1 \beta$ on chondrocytes, we applied 2D-DIGE to chondrocyte cellular proteins. Then, we separated proteins extracted from unstimulated chondrocytes (control) and the stimulated chondrocytes (treated with Il-1 $\beta$, celecoxib, Il- $\beta$ + celecoxib) by 2DE (Figure 1 ). As a result, more than 1100 protein spots were detected per gel image, of which 86 protein spots showed significantly different intensity among the 4 groups.

\subsection{Effects of Celecoxib on Chondrocytes}

In the 2D-GIGE comparison between the protein profiles of chondrocytes treated with celecoxib alone and those



Figure 1. Proteins extracted from the chondrocytes from 3 patients (P1, P2, P3) and stimulated chondrocytes (IL- $1 \beta$, celecoxib and IL- $1 \beta+$ celecoxib) were applied to 2-dimentional electrophoresis (2-DE). More than 1100 protein spots were detected per gel image, of which 86 protein spots showed significantly different intensity among the 4 groups. 
of control, 16 protein spots increased their intensity by celecoxib up to more than 1.5 folds and 12 protein spots down to less than 1/1.5 folds with statistical significance. Out of these protein spots, 4 spots increased their intensity up to more equal 2.0 folds and 3 spots down to less equal 2.0 folds, as shown in Table 1.

We then tried to identify these 28 protein spots $(1.5 \leq$ or $1 / 1.5 \geq)$ by MALDI-TOF-TOF/MS and could identified 11 proteins out of them as summarized in Table 2. Each spot on the 2D gel was shown in Figure 2.

\subsection{Effects of Celecoxib on IL-1 $\beta$ Treated Chondrocytes}

Next, we tried to elucidate whether celecoxib cancels the effects of IL- $\beta$ on chondrocytes. We obtained 11 protein spots of which intensity was significantly increased by the IL- $1 \beta$ stimulation. In 4 out of the 11 protein spots, simultaneous addition of celecoxib decreased the intensity at the levels of control. Similarly, we obtained 4 protein spots of which intensity was significantly decreased by the IL- $1 \beta$ stimulation. In 3 out of the 4 protein spots, simultaneous addition of celecoxib increased to the levels of control. Thus, we obtained 7 protein spots in all, of which intensity was resumed by addition of celecoxib as shown in Table 3 and Figure 3 . We tried to identify the 7 proteins by mass spectrometry and could identify 2 proteins out of them, as listed in Table 4. Figure 4 shows intensity of CD200R1 and moesin spots visualized by 3D images.

\section{Discussion}

Several comprehensive proteomic analyses of cancer cells treated with celecoxib have been studied in lung can-

Table 1. Difference of intensity and the number of protein spots.

\begin{tabular}{ccc}
\hline Difference of intensity (celecoxib/control) & Number of spots \\
\hline $3.0 \leq$ & 0 \\
$2.0 \leq$ & 4 \\
$1.5 \leq$ & 16 \\
$1 / 1.5 \geq$ & 12 \\
$1 / 2.0 \geq$ & 3 \\
$1 / 3.0 \geq$ & 0 \\
\hline
\end{tabular}

Table 2. Identification of chondrocyte proteins affected by celecoxib.

\begin{tabular}{|c|c|c|c|c|}
\hline Spot No. & MW & & $\begin{array}{c}\text { Difference } \\
\text { (celecoxib/control) }\end{array}$ & Protein \\
\hline 59 & 130 & $(5.2)$ & -1.37 & Alpha-actinin-4 (ACTN4_HUMAN) \\
\hline 628 & 47 & $(5.8)$ & -2.39 & ATPase family AAA domain-containing protein 3C (ATD3C_HUMAN) \\
\hline 453 & 55 & $(4.7)$ & -1.59 & $\begin{array}{l}\text { 1) Tubulin beta chain (TBB5_HUMAN) } \\
\text { 2) Tubulin beta-2B chain (TBB2B_HUMAN) }\end{array}$ \\
\hline 630 & 42 & $(8.8)$ & -1.52 & Serpin H1 (SERPH_HUMAN) \\
\hline 601 & 46 & $(5.0)$ & -2.08 & cAMP-dependent protein kinase type II-beta regulatory subunit (KAP3_HUMAN) \\
\hline 615 & 47 & $(5.4)$ & 2.11 & Apolipoprotein A-V (APOA5_HUMAN) \\
\hline 306 & 78 & $(4.9)$ & 2.55 & 78 kDa glucose-regulated protein (GRP78_HUMAN) \\
\hline 296 & 78 & $(5.0)$ & 2.63 & 78 kDa glucose-regulated protein (GRP78_HUMAN) \\
\hline 362 & 80 & $(5.5)$ & 1.5 & Glutamate carboxypeptidase 2 (FOLH1_HUMAN) \\
\hline 290 & 63 & $(5.4)$ & 1.57 & Stress-70 protein, mitochondrial (GRP75_HUMAN) \\
\hline 324 & 63 & $(5.6)$ & 1.9 & Sorting nexin-9 (SNX9_HUMAN) \\
\hline
\end{tabular}


Table 3. Number of protein spots that were affected by IL- $1 \beta$ and celecoxib.

\begin{tabular}{cccc}
\hline & $\mathrm{IL}-1 \beta /$ control $(p<0.05)$ & & IL-1 $\beta+$ celecoxib/IL-1 $\beta(p<0.05)$ \\
\hline Increase & 11 & Increase & $4^{*}$ \\
& & Decrease & $3^{*}$ \\
Decrease & 4 & Increase & 1 \\
Total & 15 & Decrease & 9 \\
\hline
\end{tabular}

*Intensity was resumed by addition of celecoxib.

Table 4. Proteins whose intensity was affected by IL- $1 \beta$ and resumed by addition of celecoxib.

\begin{tabular}{|c|c|c|c|c|c|c|}
\hline \multirow{2}{*}{ Spot No. } & \multirow{2}{*}{\multicolumn{2}{|c|}{$\begin{array}{c}\text { MW pI } \\
\text { (Observed) }\end{array}$}} & \multicolumn{3}{|c|}{ Relative difference } & \multirow{2}{*}{ Protein } \\
\hline & & & Control & IL-1 $\beta$ & IL- $1 \beta+$ celecoxib & \\
\hline 711 & 36 & 6 & 1 & 1.6 & 0.91 & $\begin{array}{l}\text { Cell surface glycoprotein CD200 receptor } 1 \\
\text { (MO2R1_HUMAN) }\end{array}$ \\
\hline 349 & 63 & 6 & 1 & 0.69 & 1.2 & Moesin (MOES_HUMAN) \\
\hline
\end{tabular}

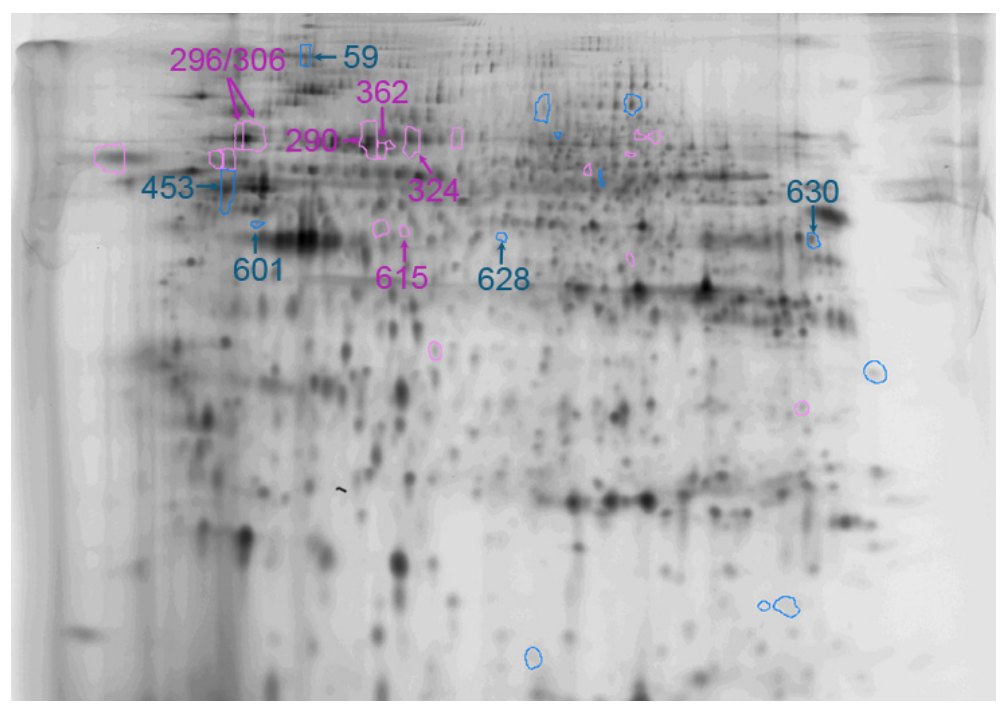

Figure 2. Protein spots and their spot No. on 2D-gel.

cer, oral squamous cell carcinoma and colorectal carcinoma [22]-[24]. Another study used cardiomyocytes to investigate the cardiovascular toxicity of NSAIDs including celecoxib [25]. The present study is believed to be the first one to investigate the effects of celecoxib on OA chondrocytes.

With the proteomic analysis, no less than 86 proteins were found to be affected by celecoxib and/or IL- $1 \beta$ in this study. Out of these 86 proteins, we could identify 5 decreased proteins and 6 enhanced proteins in chondrocytes treated with celecoxib. COX-2 was not implicated in this condition, as chondrocytes from OA as well as normal cartilage expressed extremely low levels of $\mathrm{PGE}_{2}$ and COX-2 mRNA when incubated in an unstimulated condition [26]. Thus, the modification of these proteins was mediated by mechanisms unrelated to COX-2. Dimethyl-celecoxib, which is a close structural analogue of celecoxib, lacks the inhibitory function of COX-2, and has antitumor effects through activation of endoplasmic stress in tumor cells [27].

Two proteins out of the 5 decreased ones were cytoskeletons, actin and tubulin. The remaining proteins were ATPase family AAA domain-containing protein 3C, serpin $\mathrm{H} 1$ and cAMP-dependent protein kinase type II-beta regulatory subunit. The AAA+ (ATPases associated with various cellular activities) family is a large and func- 


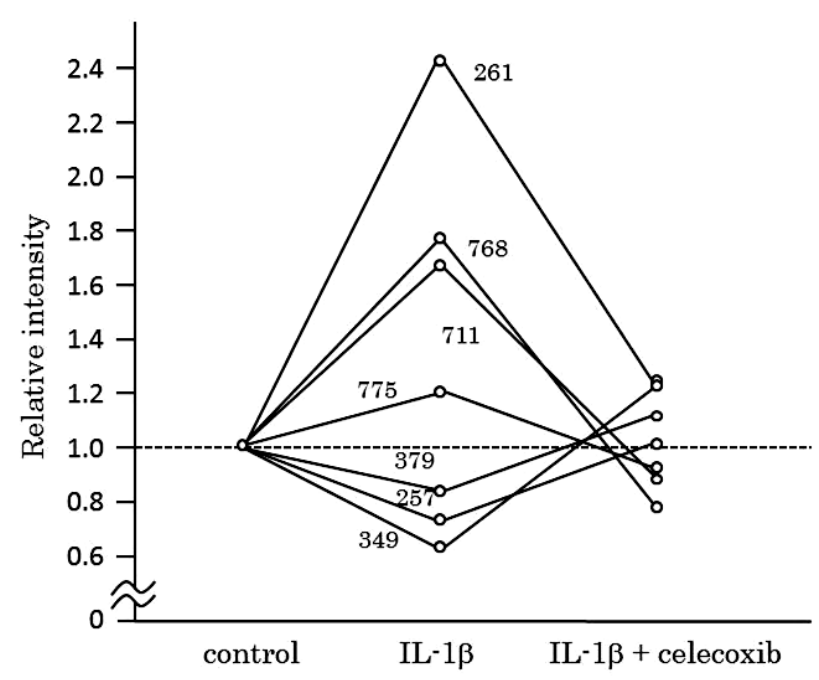

Figure 3. Protein spots of which intensity significantly changed by IL- $1 \beta$ and resumed by addition of celecoxib.

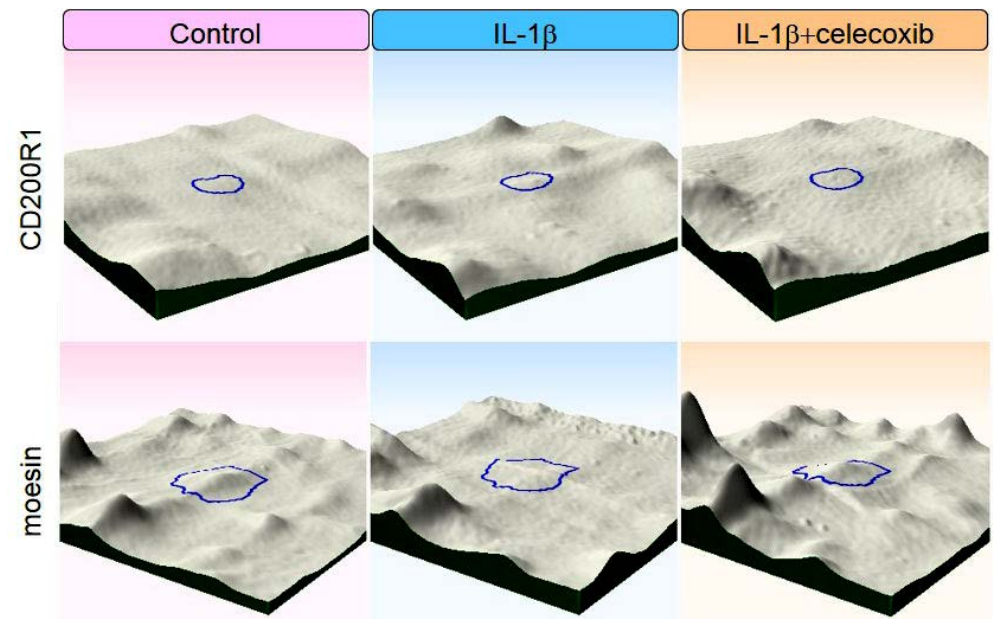

Figure 4. Intensity of CD200R1 and moesinspots werevisualized by 3D images.

tionally diverse group of enzymes that are able to induce conformational changes in a wide range of substrate proteins [28]. Serpin $\mathrm{H} 1$ is one of the serine protease inhibitors and is commonly known as heat shock protein 47 (HSP47). HSP47/Serpin H1 is a molecular chaperon and maintains collagen biosynthesis. Antibodies against it are found in autoimmune diseases such as rheumatoid arthritis and systemic lupus erythematodes [29]. HSP47 is a stress protein that is induced under some stress in endoplasmic reticulum (ER). In early OA in a mouse model, HSP47 mRNA was up-regulated associated with IL-1 $\beta$, IL-6 and TNF $\alpha$, suggesting that celecoxib may suppress the stress in OA chondrocytes [30]. The significance of cAMP-dependent protein kinase and AAA+ family protein on osteoarthritis is unclear as far as we have found in the literature.

The 6 enhanced proteins included apolipoprotein A-V, $78 \mathrm{kDa}$ glucose-regulated protein (GRP78), glutamate carboxy peptidase 2, mitochondrial stress-70 protein and sorting nexin-9. GRP78 was identified from 2 different spots. Apolipoprotein A-V was first found in 2001, and it maintains plasma levels of triglyceride [31]. Sorting nexin 9 is widely expressed and plays a role in endocytosis [32]. An alternative name for mitochondrial stress70 protein is $75 \mathrm{Kd}$ glucose regulated protein (GRP75). It is located in mitochondria and causes cell proliferation [33]. No implication of chondrocytes in OA with these proteins has been reported as yet. On the other hand, GRP78 was physiologically induced by starvation [34], and interestingly, also by dimethyl celecoxib, the analog of celecoxib that lacks COX-2 activity [35], which suggested that GRP78 induction was COX-2 independent. Proteomic analysis of human chondrocytes has shown that GRP78 as well as GRP94 increased in late stage OA 
[36], and advanced glycation end products (AGEs) induced GRP78 in chondrocytes [37]. GRP78 is an ER chaperon and is induced by stress to refold unfolded proteins, however, sustained ER stress leads to an inflammatory response and apoptosis [38]. Under stress, GRP78 is expressed and its specific overexpression was reported to reduce apoptosis in Chinese hamster ovary cells [39]. Thus, appropriate induction of GRP78 by celecoxib may have a chondroprotective effect, in part.

We identified 2 proteins whose IL- $1 \beta$-induced expression was neutralized by celecoxib; CD200 receptor increased and moesin decreased with IL- $1 \beta$ stimulation, and both returned to baseline by addition of celecoxib. CD200 receptor (CD200R) is a ligand of CD200, also known as OX-2. Expression of CD200R is found in the macrophage lineage cells and delivers an inhibitory signaling [40]. Activation of CD200R by CD200-Fc ameliorates collagen-induced arthritis in mice [41]. Expression of CD200R in chondrocytes has not been studied yet, and further research is needed for the function of CD200R in chondrocytes of OA. Moesin together with Erzin and Radixin serves as a nexus between cell membrane and underlying cytoskeleton. It regulates signaling pathways by linking transmembrane receptors and downstream signaling components [42]. Though there is very little knowledge regarding the effects of moesin on chondrocytes, increased phosphorylation of moesin has been observed on stretched chondrocytes [43].

Some limitations of our study should be mentioned. First, the clinical serum concentration of celecoxib was not more than $1 / 10$ of the concentration used in this study. As the aim of this study was to identify candidate proteins, we used higher concentration to detect as much potent proteins as possible. Validation of each protein should be necessary in the next step. Second, a number of patients who provided chondrocytes was only 3 . As a larger number of patients are required for representing OA, validation of each protein will be necessary using an appropriate number of patients. Even though, it should be emphasized that differences of protein expression reached statistical significance in this study. Lastly, chondrocytes from healthy subjects were not evaluated as a control. Our previous study showed that responses of normal chondrocytes by IL-1 stimulation were different from those of OA [26] and the results might be different. While celecoxib is used for patients with symptom of OA, normal chondrocytes should also be evaluated as a scientific interest.

\section{Conclusion}

In conclusion, the protein profile of OA chondrocytes was found to change after the administration of celecoxib. AAA+ protein, HSP47/Serpin, cAMP-dependent protein kinase type II-beta regulatory subunit, alpha-actin-4 and tubulin decreased with administration of celecoxib, and apoplipoprotein $\mathrm{A}-\mathrm{V}$, glutamate carboxipeptide 2, mitochondrial stress-70 protein, sorting nexin-9 and GRP78 increased with addition of celecoxib. Of these, GRP78 is a stress protein, and overexpression of it may have a chondroprotective effect by inhibiting apoptosis. In the present study, celecoxib modulated IL- $1 \beta$-stimulated chondrocytes, and CD200R and moesin were identified as two such resulting proteins. Further investigation is needed to elucidate the function of eachprotein in OA.

\section{Acknowledgements}

HN received a research grant from Pfizer Inc.

\section{References}

[1] Dillon, C.F., Rasch, E.K., Gu, Q. and Hirsch, R. (2006) Prevalence of Knee Osteoarthritis in the United States: Arthritis Data from the Third National Health and Nutrition Examination Survey 1991-94. The Journal of Rheumatology, 33, 2271-2279.

[2] Muraki, S., Oka, H., Akune, T., Mabuchi, A., En-yo, Y., Yoshida, M., et al. (2009) Prevalence of Radiographic Knee Osteoarthritis and Its Association with Knee Pain in the Elderly of Japanese Population-Based Cohorts: The ROAD Study. Osteoarthritis Cartilage, 17, 1137-1143. http://dx.doi.org/10.1016/j.joca.2009.04.005

[3] Gabriel, S.E., Crowson, C.S., Campion, M.E. and O’Fallon, W.M. (1997) Indirect and Nonmedical Costs among People with Rheumatoid Arthritis and Osteoarthritis Compared with Nonarthritic Controls. The Journal of Rheumatology, 24, 43-48.

[4] Goldring, M.B. and Marcu, K.B.(2009) Cartilage Homeostasis in Health and Rheumatic Diseases. Arthritis Research Therapy, 11, 224. http://dx.doi.org/10.1186/ar2592

[5] Goldring, S.R. and Goldring, M.B. (2004) The Role of Cytokines in Cartilage Matrix Degeneration in Osteoarthritis. 
Clinical Orthopaedics and Related Research, 427, S27-S36. http://dx.doi.org/10.1097/01.blo.0000144854.66565.8f

[6] Middleton, J., Manthey, A. and Tyler, J. (1996) Insulin-Like Growth Factor (IGF) Receptor, IGF-I, Interleukin-1 (IL-1), and IL-6 mRNA Expressionbin Osteoarthritic and Normal Human Cartilage. Journal of Histochemistry Cytochemistry, 44, 133-141. http://dx.doi.org/10.1177/44.2.8609369

[7] Campbell, I.K., Piccoli, D.S. and Hamilton, J.A. (1990) Stimulation of Human Chondrocyte Prostaglandin E2 Production by Recombinant Human Interleukin-1 and Tumour Necrosis Factor. Biochimica et Biophysica Acta, 1051, 310318. http://dx.doi.org/10.1016/0167-4889(90)90140-9

[8] Stadler, J., Stefanovic-Racic, M., Billiar, T.R., et al. (1991) Articular Chondrocytes Synthesize Nitric Oxide in Response to Cytokines and Lipopolysaccharide. The Journal of Immunology, 147, 3915-3920.

[9] Tetlow, L.C., Adlam, D.J. and Woolley, D.E. (2001) Matrix Metalloproteinase and Proinflammatory Cytokine Production by Chondrocytes of Human Osteoarthritic Cartilage: Associations with Degenerative Changes. Arthritis Rheumatology, 44, 585-594. http://dx.doi.org/10.1002/1529-0131(200103)44:3<585::AID-ANR107>3.0.CO;2-C

[10] Fernandes, J.C., Martel-Pelletier, J. and Pelletier, J.P. (2002) The Role of Cytokines in Osteoarthritis Pathophysiology. Biorheology, 39, 237-246.

[11] Zhang, W., Nuki, G., Moskowitz,. R.W., et al. (2010) OARSI Recommendations for the Management of Hip and Knee Osteoarthritis: Part III: Changes in Evidence Following Systematic Cumulative Update of Research Published through January 2009. Osteoarthritis Cartilage, 18, 476-499. http://dx.doi.org/10.1016/j.joca.2010.01.013

[12] Hochberg, M.C., Altman, R.D., April, K.T., et al. (2012) American College of Rheumatology 2012 Recommendations for the Use of Nonpharmacologic and Pharmacologic Therapies in Osteoarthritis of the Hand, Hip, and Knee. Arthritis Care \& Research (Hoboken), American College of Rheumatology, 64, 465-474.

[13] Palmoski, M.J. and Brandt, K.D. (1985) Proteoglycan Depletion, Rather than Fibrillation, Determines the Effects of Salicylate and Indomethacin on Osteoarthritic Cartilage. Arthritis Rheumatology, 28, 548-553. http://dx.doi.org/10.1002/art.1780280514

[14] Huskisson, E.C., Berry, H., Gishen, P., Jubb, R.W., and Whitehead, J. (1995) Effects of Antiinflammatory Drugs on the Progression of Osteoarthritis of the Knee. LINK Study Group. Longitudinal Investigation of Nonsteroidal Antiinflammatory Drugs in Knee Osteoarthritis. The Journal of Rheumatology, 22, 1941-1946.

[15] Dingle, J.T. (1999) The Effects of NSAID on the Matrix of Human Articular Cartilages. Zeitschrift für Rheumatologie, 58, 125-129. http://dx.doi.org/10.1007/s003930050161

[16] Nakamura, H., Masuko, K., Yudoh, K., Kato, T. and Nishioka, K. (2007) Effects of Celecoxib on Human Chondrocytes-Enhanced Production of Chemokines. Clinical and Experimental Rheumatology, 25, 11-16.

[17] Zweers, M.C., de Boer, T.N., van Roon, J., Bijlsma, J.W., Lafeber, F.P. and Mastbergen, S.C. (2011) Celecoxib: Considerations Regarding Its Potential Disease-Modifying Properties in Osteoarthritis. Arthritis Research Therapy, 13, 239. http://dx.doi.org/10.1186/ar3437

[18] Chevalier, F. (2010) Highlights on the Capacities of “Gel-Based” Proteomics. Proteome Science, 8, 23. http://dx.doi.org/10.1186/1477-5956-8-23

[19] Kamada, T., Kurokawa, M.S., Kato, T., et al. (2012) Proteomic Analysis of Bone Marrow-Adherent Cells in Rheumatoid Arthritis and Osteoarthritis. International Journal of the Rheumatic Diseases, 15, 169-178. http://dx.doi.org/10.1111/j.1756-185X.2012.01702.x

[20] Altman, R., Asch, E., Bloch, D., et al. (1986) Development of Criteria for the Classification and Reporting of Osteoarthritis. Classification of Osteoarthritis of the Knee. Diagnostic and Therapeutic Criteria Committee of the American Rheumatism Association. Arthritis Rheumatology, 29, 1039-1049. http://dx.doi.org/10.1002/art.1780290816

[21] McAdam, B.F., Catella-Lawson, F., Mardini, I.A., Kapoor, S., Lawson, J.A. and FitzGerald, G.A. (1999) Systemic Biosynthesis of Prostacyclin by Cyclooxygenase (COX)-2: The Human Pharmacology of a Selective Inhibitor of COX-2. Proceedings of the National Academy of Sciences of the USA, 96, 272-277. http://dx.doi.org/10.1073/pnas.96.1.272

[22] Tan, Y.H., Lee, K.H., Lin, T., Sun, Y.C., Hsieh-Li, H.M., Juan, H.F. and Wang, Y.C. (2008) Cytotoxicity and Proteomics Analyses of OSU03013 in Lung Cancer. Clinical Cancer Research, 428, 181-192.

[23] Lee, E.J., Kim, S.H., Kwark, Y.E. and Kim, J. (2006) Heterogeneous Nuclear Ribonuclear Protein C Is Increased in the Celecoxib-Induced Growth Inhibition of Human Oral Squamous Cell Carcinoma. Experimental and Molecular Medicine, 38, 203-209. http://dx.doi.org/10.1038/emm.2006.25

[24] Lou, J., Fatima, N., Xiao, Z., Stauffer, S., Smythers, G., Greenwald, P., et al. (2006) Proteomic Profiling Identifies Cyclooxygenase-2-Independent Global Proteomic Changes by Celecoxib in Colorectal Cancer Cells. Cancer Epidemiology, Biomarkers Prevention, 15, 1598-1606. http://dx.doi.org/10.1158/1055-9965.EPI-06-0216

[25] Baek, S.M., Ahn, J.S., Noh, H.S., Park, J., Kang, S.S. and Kim, D.R. (2010) Proteomic Analysis in NSAIDs-Treated 
Primary Cardiomyocytes. Journal of Proteomics, 73, 721-732. http://dx.doi.org/10.1016/j.jprot.2009.10.004

[26] Nakamura, H., Shibakawa, A., Tanaka, M., Kato, T. and Nishioka, K. (2004) Effects of Glucosamine Hydrochloride on the Production of Prostaglandin E2, Nitric Oxide and Metalloproteases by Chondrocytes and Synoviocytes in Osteoarthritis. Clinical and Experimental Rheumatology, 22, 293-299.

[27] Pyrko, P., Kardosh, A., Liu, Y.T., Soriano, N., Xiong, W.Y., Chow, R.H., et al. (2007) Calcium-Activated Endoplasmic Reticulum Stress as a Major Component of Tumor Cell Death Induced by 2,5-Dimethyl-Celecoxib, a Non-Coxib Analogue of Celecoxib. Molecular Cancer Therapeutics, 6, 1262-1275. http://dx.doi.org/10.1158/1535-7163.MCT-06-0629

[28] Hanson, P.I. and Whiteheart, S.W. (2005) AAA+ Proteins: Have Engine, Will Work. Nature Reviews Molecular Cell Biology, 6, 519-529. http://dx.doi.org/10.1038/nrm1684

[29] Morito, D. and Nagata, K. (2012) ER Stress Proteins in Autoimmune and Inflammatory Diseases. Frontiers in Immunology, 3, 48. http://dx.doi.org/10.3389/fimmu.2012.00048

[30] Takahashi, K., Kubo, T., Goomer, R.S., Amiel, D., Kobayashi, K., Imanishi, J., Teshima, R. and Hirasawa, Y. (1997) Analysis of Heat Shock Proteins and Cytokines Expressed during Early Stages of Osteoarthritis in a Mouse Model. Osteoarthritis and Cartilage, 5, 321-329. http://dx.doi.org/10.1016/S1063-4584(97)80036-2

[31] Sharma, V., Ryan, R.O. and Forte, T.M. (2012) Apolipoprotein A-V Dependent Modulation of Plasma Triacylglycerol: A Puzzlement. Biochimica et Biophysica Acta, 1821, 795-799. http://dx.doi.org/10.1016/j.bbalip.2011.12.002

[32] Lundmark, R. and Carlsson, S.R. (2003) Sorting Nexin 9 Participates in Clathrin-Mediated Endocytosis through Interactions with the Core Components. Journal of Biological Chemistry, 278, 46772-46781. http://dx.doi.org/10.1074/jbc.M307334200

[33] Mizzen, L.A., Chang, C., Garrels, J.I. and Welch, W.J. (1989) Identification, Characterization, and Purification of Two Mammalian Stress Proteins Present in Mitochondria, grp 75, a Member of the hsp 70 Family and hsp 58, a Homolog of the Bacterial groEL Protein. Journal of Biological Chemistry, 264, 20664-20675.

[34] Fu, Y., Li, J. and Lee, A.S. (2007) GRP78/BiP Inhibits Endoplasmic Reticulum BIK and Protects Human Breast Cancer Cells against Estrogen Starvation-Induced Apoptosis. Cancer Research, 67, 3734-3740. http://dx.doi.org/10.1158/0008-5472.CAN-06-4594

[35] Virrey, J.J., Liu, Z., Cho, H.Y., Kardosh, A., Golden, E.B., Louie, S.G., et al. (2010) Antiangiogenic Activities of 2,5-Dimethyl-Celecoxib on the Tumor Vasculature. Molecular Cancer Therapeutics, 9, 631-641. http://dx.doi.org/10.1158/1535-7163.MCT-09-0652

[36] Ruiz-Romero, C., Carreira, V., Rego, I., Remeseiro, S., López-Armada, M.J. and Blanco, F.J. (2008) Proteomic Analysis of Human Osteoarthritic Chondrocytes Reveals Protein Changes in Stress and Glycolysis. Proteomics, 8, 495-507. http://dx.doi.org/10.1002/pmic.200700249

[37] Rasheed, Z. and Haqqi, T.M. (2012) Endoplasmic Reticulum Stress Induces the Expression of COX-2 through Activation of eIF2 $\alpha$, p38-MAPK and NF- $\kappa$ B in Advanced Glycation End Products Stimulated Human Chondrocytes. Biochimica et Biophysica Acta, 1823, 2179-2189. http://dx.doi.org/10.1016/j.bbamcr.2012.08.021

[38] Brown, M.K. and Naidoo, N. (2012) The Endoplasmic Reticulum Stress Response in Aging and Age-Related Diseases. Frontiers in Physiology, 3, 263. http://dx.doi.org/10.3389/fphys.2012.00263

[39] Reddy, R.K., Mao, C., Baumeister, P., Austin, R.C., Kaufman, R.J. and Lee, A.S. (2003) Endoplasmic Reticulum Chaperone Protein GRP78 Protects Cells from Apoptosis Induced by Topoisomerase Inhibitors: Role of ATP Binding Site in Suppression of Caspase-7 Activation. Journal of Biological Chemistry, 278, 20915-20924. http://dx.doi.org/10.1074/jbc.M212328200

[40] Barclay, A.N. (1981) Different Reticular Elements in Rat Lymphoid Tissue Identified by Localization of Ia, Thy-1 and MRC OX 2 Antigens. Immunology, 44, 727-736.

[41] Hoek, R.M., Ruuls, S.R., Murphy, C.A., Wright, G.J., Goddard, R., Zurawski, S.M., et al. (2000) Down-Regulation of the Macrophage Lineage through Interaction with OX2 (CD200). Science, 290, 1768-1771. http://dx.doi.org/10.1126/science.290.5497.1768

[42] Neisch, A.L. and Fehon, R.G. (2011) Ezrin, Radixin and Moesin: Key Regulators of Membrane-Cortex Interactions and Signaling. Current Opinion in Cell Biology, 23, 377-382. http://dx.doi.org/10.1016/j.ceb.2011.04.011

[43] Piltti, J., Häyrinen, J., Karjalainen, H.M. and Lammi, M.J. (2008) Proteomics of Chondrocytes with Special Reference to Phosphorylation Changes of Proteins in Stretched Human Chondrosarcoma Cells. Biorheology, 45, 323-335. 
Scientific Research Publishing (SCIRP) is one of the largest Open Access journal publishers. It is currently publishing more than 200 open access, online, peer-reviewed journals covering a wide range of academic disciplines. SCIRP serves the worldwide academic communities and contributes to the progress and application of science with its publication.

Other selected journals from SCIRP are listed as below. Submit your manuscript to us via either submit@scirp.org or Online Submission Portal.
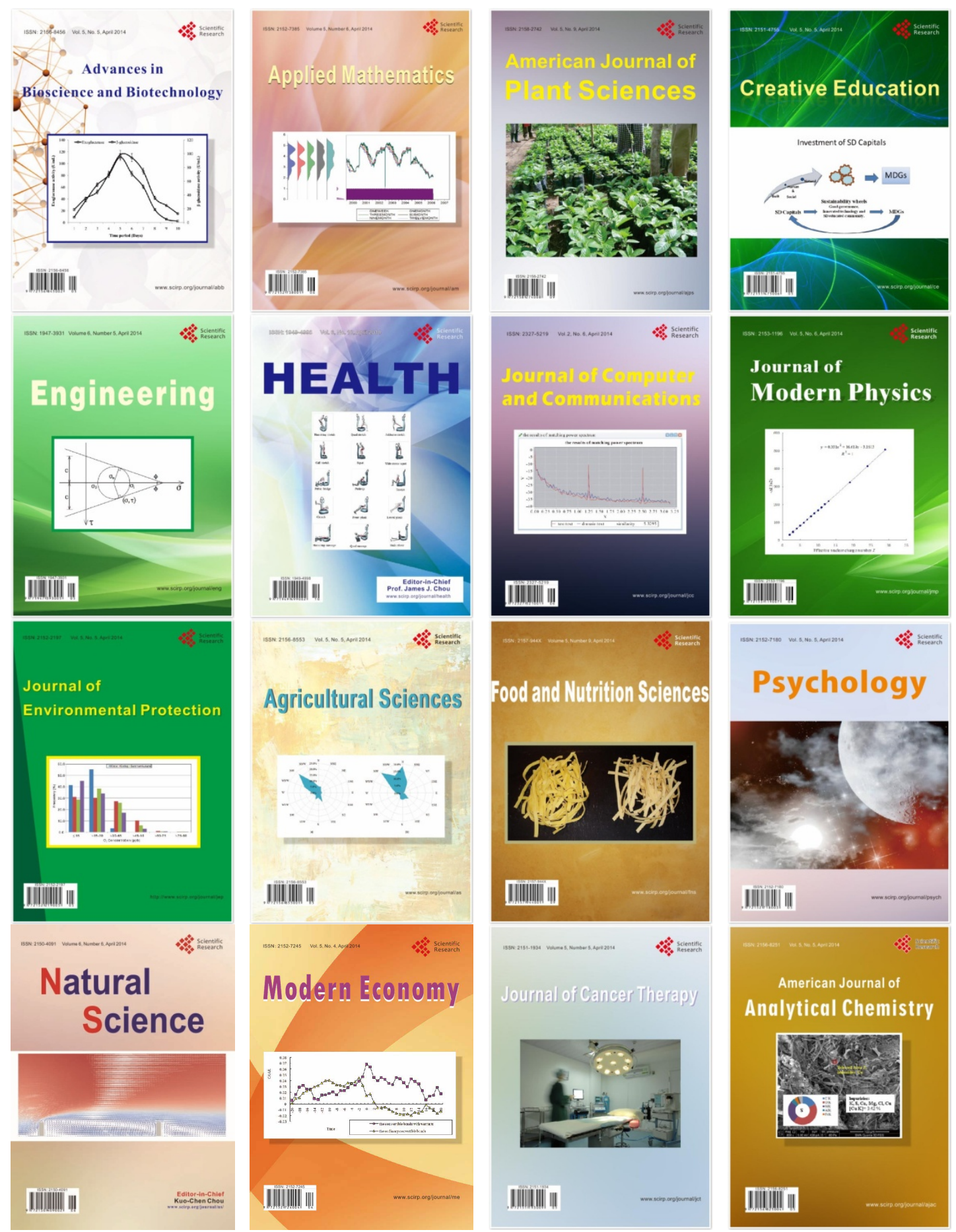